\title{
Filosofia da Educação e formação de professores no velho dilema entre teoria e prática ${ }^{1}$
}

\section{Philosophy of Education and formation of teachers in the old dilemma between theory and practice}

\author{
Amarildo Luiz Trevisan ${ }^{2}$
}

\begin{abstract}
RESUMO
A discussão sobre a formação de professores no Brasil parece seguir o deslocamento do polo da teoria para o polo da prática, ou seja, do "dever ser" ao "fazer" do professor, acompanhando a mudança de paradigma que norteou o surgimento da compreensão moderna do conhecimento. Entretanto, o que se observa no modelo proposto, subjacente à legislação, é uma tentativa extremamente problemática de minimizar a sua distância, na medida em que apenas se afirma de outro modo a mesma dicotomia. Não há uma solução ou equacionamento correto, pois somente se diluiu a prática ao longo do percurso teórico, sem compreender devidamente o significado da virada da prática. Por isso, o objetivo do texto é propor uma reformulação do dilema entre teoria e prática desenvolvido pela educação brasileira enquanto cristalizado nas normativas sobre a formação de professores, a partir da reflexão sobre uma Filosofia da Educação inspirada na teoria do reconhecimento social do outro.

Palavras-chave: filosofia da educação; formação de professores; teoria; prática; reconhecimento do outro.
\end{abstract}

${ }^{1}$ Este artigo é resultado do projeto de pesquisa Teoria e Prática da Formação no Reconhecimento do Outro, financiado com bolsa produtividade em pesquisa do CNPq. Agradeço às revisões e sugestões dos profs. Claudio Almir Dalbosco (UPF), Catia Piccolo Viero Devechi (UnB) e Maiane H. Ourique (UFPel).

${ }^{2}$ Professor do Programa de Pós-Graduação de Educação da Universidade Federal de Santa Maria (PPGE/CE/UFSM) e líder do Grupo de Pesquisa Formação Cultural, Hermenêutica e Educação (www.ufsm.br/gpforma), Brasil. e-mail: amarildoluiz@terra.com.br 


\begin{abstract}
The discussion about the formation of teachers in Brazil seems to follow the movement from the theory pole to the practice pole, that is, from the "must be" to the "do" of the teacher, following the paradigm shift that guided the emergence of the modern understanding of knowledge. However, what is observed in the proposed model, underlying the legislation, is a highly problematic attempt to minimize its distance, as it just states otherwise the same dichotomy. There is not correct solution or equation, because it just dilutes the practice throughout theoretical route, without understanding properly the meaning of the practice turning. Therefore, the paper aims at proposing a reformulation of the relationship between theory and practice developed by the Brazilian education, while crystallized in the rules about formation of teachers, from the reflection on a Philosophy of Education inspired by the theory of social recognition of the other.
\end{abstract}

Keywords: philosophy of education; formation of teachers; theory; practice; recognition of the other.

A aversão à teoria, característica de nossa época, seu atrofiamento de modo nenhum casual, sua proscrição pela impaciência que pretende transformar o mundo sem interpretá-lo, enquanto, em seu devido contexto, afirmavase que os filósofos até então tinham apenas interpretado - tal aversão à teoria constitui a fragilidade da práxis (ADORNO, 1995, p. 211).

\title{
Considerações iniciais
}

Nos últimos anos têm surgido importantes iniciativas no campo filosóficopedagógico interessadas em contribuir mais concretamente para o equacionamento dos problemas da Educação. Além de tematizar a relação entre Filosofia e Educação, potencializando reflexões importantes para os diversos contextos pedagógicos, a partir do referencial de grandes pensadores da Filosofia, estes estudos chamam a atenção para a importância do conceito de formação em sentido amplo. Inspiradas nas grandes experiências realizadas no Ocidente - a Paideia grega, a Humanitas latina e a Bildung alemã -, estas pesquisas procuram discutir os problemas educativos sob a perspectiva de valorização da cultura e suas repercussões no contexto contemporâneo. Porém, observa-se um considerável crescimento da produção nestes mesmos grupos de pesquisa direcionado cada vez mais para o problema da formação docente, considerada o verdadeiro "calcanhar de Aquiles" da educação. 
Por um lado, é notório que o debate tem se acentuado nos últimos tempos porque a crise das soluções propostas por outros modelos - como a do colapso da imagem do docente como demiurgo criador da cidadania (ROCHA, 2004, p. 155) - tem aberto espaços para a reflexão filosófica. Esta discussão ficou bem evidente ultimamente em vários artigos e livros ${ }^{3}$, bem como em diversos trabalhos apresentados no GT Filosofia da Educação, da ANPEd Nacional. Dos 15 trabalhos aprovados na $30^{\mathrm{a}}$ Reunião Anual da ANPEd Nacional, por exemplo, realizada em 2007, pelo menos 6 se direcionaram à discussão de alguns modelos ou imagens de docência a partir de reflexões oriundas de diferentes referenciais filosóficos. Esses dados constituem uma pequena amostra da produção de alguns grupos de pesquisa que trabalham com Filosofia da Educação, no Brasil, relacionando o problema da formação com a realidade dos professores.

Mas, por outro lado, cabe observar que estas pesquisas no campo teóricofilosófico têm sido alimentadas, em grande medida, pelo debate que se estabeleceu sobre a relação entre teoria e prática na formação de professores, questão esta que atravessa a relação entre Filosofia e Educação durante toda a história do ocidente ${ }^{4}$. O velho dilema entre teoria e prática volta ao centro do debate, tornando-se atualmente um dos principais eixos articuladores da formação de professores nos cursos de licenciatura do Brasil. Como não poderia deixar de ser, o foco maior do debate no campo da Filosofia da Educação é voltado para a compreensão subjacente à discussão entre teoria e prática, que serve de base à legislação educacional (BRASIL, 2001), a qual segue as ideias de autores como César Coll e Perrenoud. Se os PCNs seguiram o modelo proposto por

\footnotetext{
${ }^{3}$ Entre outras produções com base filosófica não menos importantes, destacamos os textos "Sobre a atualidade dos tabus com relação aos professores", de Antonio A. Zuin; "Hermenêutica e educação: desafios da hermenêutica na formação dialógica do docente", de Eldon Henrique Mühl; $D a$ figura do mestre, de Marlene de Souza Dozol e "Três lições de filosofia da educação", de Walter Omar Kohan; e Terapia de Atlas: pedagogia e formação docente na pós-modernidade, de Amarildo Luiz Trevisan.

${ }^{4} \mathrm{~A}$ racionalidade de nosso sistema de crenças e valores, ou seja, a racionalidade ocidental, que dividiu o mundo em aparência e essência, corpo e alma, normativo e vivido, teoria e prática e demais binômios aparentemente irreconciliáveis, é baseada na suposição de um mundo mais permanente por detrás de um mundo mutável e aparente. Ela surgiu a partir do platonismo, recebeu reforço na filosofia moderna (epistemologia) e mais tarde no positivismo. Por isso, não é capaz de dar conta analiticamente da formação do professor no ambiente de complexidade dos novos fenômenos culturais. Esses novos fenômenos criaram uma realidade artificial (a virtualidade, o ciberespaço), que produz, como afirma Matos, "objetos sem imagens e imagens sem objetos" (1999, p. 73). Este é um dos motivos pelos quais não se sustenta mais no ambiente pedagógico a ideia de "essencializar" conhecimentos, por exemplo, o que repercute fortemente na performance da docência, suas imagens e autoimagens. O artigo "Um professor no close da intolerância: a pedagogia entre imagem e opinião pública" (TREVISAN, 2006) aborda algumas consequências desta discussão para o campo da formação de professores.
} 
Coll, o desenvolvimento das competências torna-se o centro da atual reforma curricular dos cursos de licenciatura, sendo os conteúdos vistos não mais como um fim ou eixo norteador da formação profissional do professor para se tornarem, na verdade, um meio para alcançá-las. Em contraposição ao longo predomínio da teoria nos processos formativos, o modelo de Coll defende as dimensões conceitual, procedimental e atitudinal, enquanto o de Perrenoud segue o modelo da pedagogia das competências ${ }^{5}$.

É inegável que historicamente a formação de professores tem justaposto e, inclusive, confrontado a teoria e a prática, na medida em que os estágios supervisionados, por exemplo (embora não devam ser considerados apenas enquanto exercício prático, mas também como um campo privilegiado de aprendizagem teórica), eram desenvolvidos até pouco tempo atrás apenas ao final do curso. Por isso, a legislação recente tomou para si a responsabilidade de eliminar este distanciamento ${ }^{6}$. A solução dada a cada curso varia de acordo com o projeto político-pedagógico específico, porém em geral as licenciaturas têm procurado se adequar em maior ou menor grau ao encurtamento entre o normativo e o vivido. A proposta procura substituir a centralidade dos conteúdos, que deixa de ser o eixo principal da formação, para dar espaço à articulação entre a formação teórica e a formação prática, estreitando a relação da formação do professor com seu exercício profissional.

Mas será que o problema da dicotomia entre "a dimensão teórica e a dimensão prática da formação", bem como a necessidade de sua "unificação", conforme é recomendado pela legislação, se dilui no momento em que se adere ao paradigma preconizado por estas pedagogias? Até que ponto esta transição proposta na legislação educacional brasileira está causando o efeito desejado?

Apesar de estarmos inseridos na complexidade de uma sociedade que escolheu viver, a partir da modernidade, sob o primado da prática, a formação do professor não pode ficar refém de uma pretensa teoria e menos ainda do lado da simples prática, o que seria apenas uma forma de tencionar o problema

${ }^{5}$ Segundo Perrenoud (1999), as competências a serem desenvolvidas pela educação devem ser: de comprometimento com os valores inspiradores da sociedade democrática; compreensão do papel social das escolas, domínio dos conteúdos a serem socializados, aos seus significados em diferentes contextos e sua articulação interdisciplinar; domínio do conhecimento pedagógico; conhecimento de processos de investigação que possibilitem o aperfeiçoamento da prática pedagógica; e, por último, competências referentes ao gerenciamento do próprio desenvolvimento profissional.

${ }^{6} \mathrm{~A}$ Resolução CNE/CP 1/2002, de 18 de fevereiro de 2002, por exemplo, que institui as Diretrizes Curriculares Nacionais para a Formação de Professores da Educação Básica, chega a recomendar, no seu art. 12, que a prática esteja presente desde o início do curso, perpassando toda a formação do professor. Os estágios curriculares deixam então de acontecer como epílogo de um longo processo em que estiveram ausentes para se tornarem parte do dia a dia da formação. 
sem oferecer-lhe uma solução. Afinal, como refere Pimenta, "o professor pode produzir conhecimento a partir da prática, desde que na investigação reflita intencionalmente sobre ela, problematizando os resultados obtidos com o suporte da teoria. E, portanto, como pesquisador de sua própria prática" (PIMENTA, 2006, p. 43).

Por isso, neste texto pretendemos, primeiramente, defender a ideia de que a dificuldade das políticas de formação de professores em aliar teoria e prática, privilegiando a prática, significa, na verdade, a passagem de uma teoria a outra, isto é, de uma teoria normativa a uma teoria explicativa. E, segundo, propor uma reformulação da compreensão desta dicotomia baseada nos preceitos de uma Filosofia da Educação inspirada na teoria do reconhecimento social do outro, procurando evitar as armadilhas do compromisso com as instâncias teológico-metafísicas do contexto em que ela foi gestada. O intuito é despertar mais uma vez o pássaro de Minerva ${ }^{7}$, em seu compromisso históricohermenêutico com a sabedoria, para alçar o seu voo de reconhecimento com vistas a denunciar os estreitamentos reflexivos a que a formação de professores ficou submetida nesta proposta.

\section{A relação teoria e prática no modelo da legislação}

Não vamos aqui discutir exaustivamente os pressupostos teóricos presentes nos documentos e normativas legais sobre a formação de professores, mesmo porque já existe uma bibliografia bem abalizada sobre o assunto ${ }^{8}$. Apenas procuraremos exemplificar, seguindo os estudos de Ramos (2006), o porquê

${ }^{7}$ Refiro-me à citação de Hegel, no prefácio da obra Princípios da Filosofia do Direito, que diz: "Quando a Filosofia chega com a sua luz crepuscular a um mundo já a anoitecer, é quando uma manifestação de vida está prestes a findar. Não vem a Filosofia para a rejuvenescer, mas apenas reconhecê-la. Quando as sombras da noite começam a cair é que levanta voo o pássaro de Minerva" (HEGEL, 1986, p. 15).

${ }^{8}$ Diversas pesquisas no Brasil têm apontado os limites dos referenciais teóricos que embasam a legislação recente sobre a formação de professores (Cf. DELUIZ, 2001; KUENZER, 2010; PEREIRA, 2009). As produções da área de Filosofia da Educação também questionam a legislação enquanto apoiada no ideário da pedagogia das competências, como é o caso do artigo de Duarte: "As pedagogias do aprender a aprender e as ilusões da assim chamada sociedade do conhecimento". Moraes chama a atenção para o predomínio das "epistemologias da prática" na formação docente. Segundo a sua avaliação, as propostas de Shön, Tardif e Perrenoud "sinalizam a emergência de concepções mais individualizadas e subjetivas dos percursos de aprendizagem, a retomada do 'aprender a aprender', vinculado às condições atuais de adaptabilidade" (MORAES, 2009, p. 592). Já o parecer da Faculdade de Educação da UFRGS sobre os PCN's questiona a base psicológica e psicopedagógica em que foram construídos, presente na nomenclatura que enfatiza "capacidades intelectuais", "conhecimentos", "interesses" e "motivações dos alunos", ignorando outras contribuições para os estudos do currículo oriundas da Sociologia da Educação, da Sociologia do Currículo, Filosofia da Educação e Estudos Culturais (DOSSIÊ, 1996, p. 236-237). 
de a incorporação da prática pelo viés da pedagogia das competências não ter sido bem aceita pela crítica acadêmica no Brasil. Em geral, as acusações vão desde a sua subserviência ao pragmatismo ou ao neopragmatismo até a lógica do aprender fazendo, do treinamento e da adaptação. E, tendo como base a investigação de Coutinho (2008), demonstrar que mesmo com a aplicação indiscriminada das teorias das competências no campo da formação de professores não há uma transição da visão normativa para uma visão prática, mas sim a passagem para uma teoria explicativa.

Ramos, em seu livro A pedagogia das competências: autonomia ou adaptação?, que resultou de sua tese de doutoramento, destaca que a origem desta pedagogia remonta, na França, ao ensino técnico, acompanhando o deslocamento conceitual próprio das transformações por que passa o capitalismo. A busca de elevação do nível de escolaridade da população, exigido pelas transformações econômicas e a inclusão das novas tecnologias no processo produtivo, próprio das complexas sociedades emergentes, faz aproximar a relação entre educação e trabalho.

E isso fez transitar a centralidade do conceito de qualificação para o de competência, acabando por este se tornar o elemento regulador tanto das relações de trabalho quanto do campo da educação. Com o tempo e o surgimento de novas tecnologias, novos trabalhos e novas situações cotidianas veio o questionamento do conceito de qualificação. A proposta de revisão do conceito com foco no posto de trabalho vinha ao encontro das mudanças tecnológicas que já começavam a se anunciar, requerendo modelos flexíveis e diferenciados de formação que viabilizassem o desenvolvimento de atitudes críticas e reflexivas direcionadas à prática do trabalho em geral e não somente ao exercício de uma determinada ocupação (RAMOS, 2006, p. 56).

No entanto, as acusações de Ramos a este modelo são de que as pedagogias das competências visam desenvolver os projetos pessoais de profissionalização, em detrimento de perspectivas ou de compromissos mais coletivos. Outra crítica é a de que ele se baseia no construtivismo, que prioriza a dimensão subjetiva da aquisição de conhecimentos, e também na abordagem interdisciplinar, desconsiderando dimensões sociais e históricas do processo educativo.

A distinção estabelecida por Coutinho, no artigo "A qualidade da investigação educativa de natureza qualitativa: questões relativas à fidelidade e validade", ajuda a entender por que a pedagogia das competências desenvolve uma afinidade com a teoria explicativa. Para a autora, uma pesquisa quantitativa se distingue essencialmente da qualitativa pela questão metodológica. Mesmo não compartilhando com o viés do purismo metodológico, ou seja, com a ideia 
de que entre explicar e compreender não é possível traçar aproximações ${ }^{9}$, a autora vai referir que, em tese, a primeira procede dedutivamente, ou seja, por intermédio do uso do método hipotético-dedutivo, que privilegia a explicação, enquanto a segunda, ao contrário, procede de baixo para cima, diferenciandose pela compreensão através de insights teóricos originados do contexto vivido. Portanto, de outro modo, na metodologia qualitativa a compreensão do fenômeno ocorre de maneira indutiva, num contexto em que a busca de dados não se dá em função da confirmação ou não de uma hipótese a priori.

Podemos, nesse sentido, fazer uma transposição desta discussão para entender melhor os procedimentos da pedagogia das competências, uma vez que ela busca a explicação (da competência) para os fenômenos (problemas educativos) dentro de uma lógica dedutiva. A partir da tentativa de elucidação para os casos escolares em análise, ela parte de uma hipótese já predefinida (da falta de competências, por exemplo) para, a seguir, enfrentar a busca de dados que colocam à prova a hipótese, buscando ser aceita. Porém, a valer esta separação, tal procedimento apenas reforça a imagem ou modelo do professor explicador, criticado por Rancière (2002), postura totalmente oposta à do mestre Jacotot, contrastando visivelmente com o espírito das metodologias qualitativas. Ou seja, a imagem do professor veiculada por esta pedagogia é a do "professor explicador" que, com base nas suas experiências, teria capacidade para resolver os problemas do cotidiano da profissão. Daí se compreende a insistência desta pedagogia em terminologias como "domínio" e "gerenciamento", afeito nesse sentido à lógica da explicação, da previsão e do controle.

Cabe assinalar, entretanto, que a integração entre os elementos teóricos e práticos deve ser aprimorada e acelerada, e não simplesmente negada, como foi o caso quando se deixou de lado a preocupação com os conteúdos, por exemplo. Em função das críticas à base teórica da legislação sobre a formação de professores, queremos pôr em discussão a seguir a ideia do reconhecimento social do outro como forma de melhor compreender a relação entre teoria e prática na formação do professor.

\section{Teoria e prática no reconhecimento do outro}

A teoria do reconhecimento social não é mais um novo modismo pedagógico ou da teoria filosófica. Ela tem raízes na transição do século XVIII

\footnotetext{
${ }^{9} \mathrm{~A}$ epistemologia procura definir o conhecimento por intermédio da lógica da explicação, mais afeita a uma racionalidade analítica, enquanto a hermenêutica, atuando do lado da compreensão, chama atenção para o aspecto da historicidade do conhecimento. No entanto, o debate atual caminha para encontrar saídas para este dilema, procurando fazer valer a tese de complementaridade entre explicação e compreensão, epistemologia e hermenêutica (Cf. BOMBASSARO, 2005).
} 
para o XIX, concebida por Hegel ao longo de várias obras. Porém é na Fenomenologia do espírito que Hegel irá explicitar mais claramente o sentido de sua tese. Atualmente ela vem sendo recuperada por vários autores, entre eles Ítalo Testa, como exemplifica o artigo intitulado "Intersubjetividade, natureza, sentimentos morais: a teoria crítica de A. Honneth ${ }^{10}$ e a regra de ouro", e H.-G. Flickinger, em "Os graus do reconhecimento social: a crítica de um conceito chave a partir de G. W. F. Hegel", os quais servem de base à discussão apresentada a seguir.

Ítalo Testa afirma que toda filosofia hegeliana pode ser vista como uma teoria do reconhecimento. Hegel defende inclusive que a característica básica do ser humano é a de ser um reconhecedor. É isso que o destaca do mundo natural e o impulsiona a construir cultura. "O reconhecimento", conforme assinala, "de fato, é a natureza que consente sair do estado de natureza e entrar no mundo espiritual" (TESTA, 2008, p. 114). O indivíduo transita da simples animalidade, própria do estágio natural, para o estágio da cultura, fazendo a ponte da consciência animal para a autoconsciência humana. Em síntese, Testa conclui, num primeiro momento, que ela é uma teoria bem completa, porque tenta dar conta tanto da "tendência agressiva como da cooperativa" do ser humano, promovendo uma articulação dialética dessas instâncias (TESTA, 2008, p. 119).

Além da compreensão da passagem entre natureza e cultura, a ideia do reconhecimento também apresenta relações com a educação, na medida em que compreende a liberdade humana implicada com o reconhecimento do outro, especialmente diante de circunstâncias que não estão, em absoluto, programadas geneticamente, mas que são situações imprevistas.

Até certo nível, os comportamentos altruísticos são simplesmente inatos, ou seja, conectados geneticamente, como no caso das formigas (ou também entre o relacionamento dos recém-nascidos e de seus pais), não necessitando ser transmitidos através da educação: de outra parte, porque o comportamento esteja em grau de reagir em modo flexível a eventos imprevistos, parece solicitado, dentro de formas mais complexas de evolução, o surgimento também de comportamentos individualizados que a esse ponto devem ser mediados pela educação (TESTA, 2008, p. 116).

${ }^{10}$ Ao lado de Nancy Frazer e Charles Taylor, Axel Honneth, seguidor de Habermas e da teoria crítica da Escola de Frankfurt, é um dos mais destacados intérpretes atuais da teoria do reconhecimento de Hegel. Segundo o testemunho de Mattos, "como Honneth se propõe a desenvolver uma sociologia do reconhecimento, faz-se necessário comprovar empiricamente como ocorre o processo de reconhecimento em suas diferentes dimensões, o que Hegel só fez abstrata e metafisicamente. A intenção de Honneth é desenvolver uma perspectiva aberta às modernas ciências empíricas, notadamente, à sociologia" (MATTOS, 2006, p. 87). 
Uma educação para o imprevisível pode tirar conclusões importantes deste contexto, necessitando um envolvimento tanto de caráter teórico quanto prático, dado que o reconhecimento promove igualmente a articulação entre estes elementos. Nesse sentido, Testa vai esclarecer também que Hegel "não pretende simplesmente afirmar um primado da dimensão prática em detrimento da teórica, mas, antes, colocar em discussão qualquer oposição artificial entre os dois ambientes (que, finalmente, é confirmada pela tese do primado prático)." E complementa: "Assim, a teoria do reconhecimento apresenta-se em Hegel como um conceito intermediário entre a esfera teórica e a esfera prática [...]" (TESTA, 2008, p. 100). Logo, a própria relação da teoria com a prática não é um movimento simplesmente espontâneo ou casual da espécie humana segundo Hegel, mas, sobretudo, um processo cultural derivado de uma luta por reconhecimento.

Levando adiante esta sugestão de Testa, a luta por reconhecimento presente na metáfora dialética do senhor e do escravo - poderia ser avaliada a partir da relação entre teoria e prática? É possível supor uma resposta positiva a esta indagação, na medida em que, conforme dito anteriormente, toda a obra de Hegel pode ser avaliada sob o crivo do reconhecimento.

Inclusive a famosa metáfora da viagem do pássaro de Minerva, comparada com o sentido da Filosofia, não pode ser simplesmente entendida como uma tentativa de conhecimento e sim muito mais como um voo de reconhecimento, pois a coruja bate as suas asas não pela manhã ou pela tarde, mas ao anoitecer. De igual maneira, o que pode embasar esta ideia prévia positivamente é o fato de que, na Fenomenologia do espírito, Hegel associa esta reflexão com importantes movimentos teóricos da história do pensamento: as filosofias do estoicismo, o ceticismo e o movimento dialético. Consequentemente, do mesmo modo a ideia da relação entre teoria e prática estaria subjugada a este contexto.

Assim sendo, nosso interesse aqui não é retomar a relação entre senhor e escravo nos moldes já instituídos, como oposição entre natureza ou cultura, ou ainda como protótipo da luta de classes, como fez Marx, mas sim tentar entender este enfrentamento como uma metáfora da relação entre teoria e prática na perspectiva do reconhecimento do outro. A ideia do reconhecimento confronta dois adversários, procurando dar conta, desta maneira, tanto das tendências agressivas quanto incorporando também as tendências cooperativas do ser humano.

Falando sobre a manifestação do modo mais imediato e espontâneo desta relação, Flickinger se pergunta: “O que é, à primeira vista, o senhor?" Para responder logo em seguida: 
Antes de tudo ele quer impor seu domínio ao outro sem admitir desobediência. Sua vontade de poder não discute possíveis objeções quanto à sua legitimidade. Em termos do reconhecimento podemos falar do senhor como pessoa que quer ver seu domínio reconhecido de modo imediato e incondicionalmente (FLICKINGER, 2001, p. 87).

Podemos evidenciar, em traços largos, na definição da figura do senhor o predomínio da teoria sobre a prática ao longo da história do ocidente, sendo esta última considerada escrava da teoria. Este é o momento em que, parafraseando o Nietzsche das metamorfoses do espírito, poderíamos relacionar à figura do camelo o momento do "tu deves", de afirmação da autoridade do primado da moral e da religião.

É o império do normativo, enquanto imposição da norma que pretende ser seguida sem contestação. Desde a saída da caverna platônica, quando o logos teorizador grego estendeu o seu império de maneira quase absoluta (não sem contestações, é claro), houve uma imposição de seus domínios, de tal modo que o corpo se tornou escravo da alma, as emoções da razão, a pluralidade da unidade, o diferente do homogêneo e sempre igual, enfim, a prática se tornou escrava da teoria.

Entretanto, avaliando mais atentamente esta relação assimétrica de poder, Flickinger observa que "não há domínio sem aceitação de outrem" (2001, p. 87). Cita o exemplo das prisões, em que o número de guardas é sempre infinitamente menor do que o de presos, mas o que dá garantia à ordem é o reconhecimento da sua autoridade pelos presidiários. Constata que em relações assimétricas de poder como estas, no viés lógico, se mantém a base do respeito e da consideração dos papéis sociais.

Mas que isso, ao mesmo tempo, expõe também a fragilidade de tal sistema de relação social. No viés ontológico de envolvimento com a existência, esta fragilidade fica mais exposta ainda, pois, segundo Flickinger: "Para projetar sua vontade dominadora, o senhor precisa sair de si e relacionar-se ao outro" (2001, p. 89). Ou seja, o senhor precisa confrontar-se existencialmente com um outro, que lhe põe em ameaça. Logo, há uma absoluta dependência entre ambos, pois esta relação de imposição se descobre apoiada no consentimento da outra parte. "É o outro que coloca em risco, pela sua simples presença, a pretensa autossuficiência do Eu dominador", conclui Flickinger (2001, p. 89). Em linhas gerais, podemos fazer uma analogia da saída de si do logos teorizador e o seu confronto com o momento de assunção das ciências do início da modernidade e a consequente adoção do viés do conhecimento prático, que redundou na aventura das grandes navegações que geraram o conflito com "o outro" e "o estranho" do novo mundo. 


\section{Do dever-ser ao dever-fazer do professor: um caminho sem volta?}

Hegel é fiel ao paradigma moderno de compreensão do conhecimento, na medida em que tornara claro, com seus apontamentos, que a teoria na modernidade é prática, é ação. Se ela não tiver este caráter de utilidade ou de transformação, não pode ser considerada uma teoria afinada aos princípios da modernidade, que surge em oposição ao modelo contemplativo próprio dos mundos antigo e medieval. A virada da prática no campo do conhecimento moderno não significa, entretanto, um esquecimento da teoria, esvaziada dos seus fundamentos em benefício de metodologias e técnicas. Antes disso, significa que há uma nova interdependência entre o teórico e o prático, e não a simples diluição de um dos polos contrastantes no outro. Em síntese, de certo ponto de vista, se a teoria não for prática, isto é, se ela não impelir à ação, torna-se inócua, vazia e sem sentido para o mundo em que vivemos. E, de outro, a prática nesse contexto não pode mais ser concebida como um agir empírico e sem princípios, uma vez que ela surge impulsionada justamente por uma teoria ${ }^{11}$.

Ora, a articulação entre teoria e prática proposta nos cursos de licenciaturas pela legislação procura equacionar diversos aspectos envolvidos nesta implicação, tanto relativos aos projetos pedagógicos quanto curriculares e o problema dos estágios. Entretanto, conforme dito anteriormente, ao instituir como questão central nas discussões do âmbito educacional a noção de competências, estes aspectos compartilham de uma mesma preocupação: privilegiar a prática em detrimento da teoria. Não reconhecem assim que a virada da prática não abole a instância teórica e, principalmente, "a íntima cumplicidade e reciprocidade entre teoria e prática no processo cognitivo” (MORAES, 2009, p. 590).

Na verdade, também de acordo com o que foi enfatizado antes, não há uma transição da teoria, concebida enquanto instância normativa, para a dimensão prática, mas sim de uma teoria normativa para uma explicativa. Nesta outra forma de compreensão da racionalidade, o fenômeno educativo é

\footnotetext{
${ }^{11}$ Algumas obras problematizaram a virada da discussão entre teoria e prática na modernidade, como por exemplo: Notas marginais sobre teoria e práxis. In: ADORNO, Theodor W. Palavras e sinais: modelos críticos; Maquiavel, a política e o estado moderno, de Antônio Gramsci; e Teoría y práxis: estudios de Filosofía Social, de Jürgen Habermas. Gramsci, por exemplo, vai chamar a atenção para o rompimento que promove a política no início da modernidade, especialmente em Maquiavel, com os princípios morais e religiosos vigentes à época, conferindo à política o status de ciência autônoma. Ela pode assim ficar livre e desembaraçada para impulsionar o vivido. É precisamente nesse sentido que ela se torna "ciência autônoma", isto é, uma ciência da prática política. Maquiavel não está interessado em definir algo no campo político que não produza uma ação; algo que não aconteceria se este campo permanecesse amarrado a princípios heterônomos (morais e religiosos) e, deste modo, tributário da aplicação de outras demandas.
} 
descontextualizado, ou melhor, é isolado de suas inserções histórica e social, pois o que interessa é o que o professor "efetivamente faz". A ideia de partir deste tipo de prática para pensar a formação esquece que ela própria já está informada por uma teoria, a saber, uma teoria que rejeita o contexto de descoberta, operando apenas no âmbito do contexto de validação do conhecimento, desprezando assim "os aspectos psicológicos, sociológicos e históricos, que em nosso entender constituem uma das condições de possibilidade do conhecimento" (BOMBASSARO, 2005, p. 185). Com isso, a formação acaba reduplicando a patologia a que procura se contrapor, pois, na tentativa de se livrar de algo julgado obsoleto, ela acaba se enredando nas teias de outra teoria, a qual também é distante das necessidades dos contextos pedagógicos. Aqui se entende por que Moraes critica tal artifício, acusando as "epistemologias da prática" de também recaírem no discurso prescritivo:

Tomando a educação como exemplo, com frequência o fascínio do modo de operar do ato educativo no cotidiano escolar transforma essa experiência em limite da inteligibilidade. Nas pesquisas e em eventos da área, são comuns uma supervalorização da subjetividade do trabalho docente e as célebres "histórias ou relatos do cotidiano escolar", narrativas subjetivas e/ou descritivas, quase sempre prescritivas, eivadas de "dever-ser" (MORAES, 2009, p. 590).

Um extremo a ser evitado é, portanto, escamotear o processo, impedindo o confronto com a realidade, mas outro extremo é passar para o lado oposto, o do praticismo, como quer uma pedagogia que termina por absolutizar o fato de que é "da própria prática que devem ser extraídos os fundamentos epistemológicos do ofício do professor" (MORAES, 2009, p. 591). Ao contrário, na virada da prática há um fortalecimento da instância teórica, desde o momento em que a primeira revela à segunda a fragilidade do seu domínio "absoluto", porém distanciado do real. É por isso que nossa posição é ainda mais radical, pois uma educação compromissada com a virada do paradigma da prática não apenas abole a instância teórica para, então, simplesmente partir da prática. Bem diferente é a própria teoria se transformar em ação ${ }^{12}$, recebendo a primeira um novo significado integralmente relacionado à segunda, sendo que isso the confere o caráter de cientificidade. Em lugar de "competências", sugerimos então repensar, no campo pedagógico, a ideia do "reconhecimento social do outro", pois uma Filosofia da Educação inspirada nestes contornos oferece

\footnotetext{
${ }^{12} \mathrm{~A}$ teoria da ação comunicativa, de Jürgen Habermas, é ilustrativa da característica adquirida pela teoria no contexto moderno, uma vez que ela se autocompreende inserida no universo da ação, não havendo distanciamento entre uma instância e outra do processo.
} 
ganhos no sentido propedêutico, ao preparar o terreno para evitar a ocorrência de anomalias na compreensão do processo. Afinal, do "dever-ser" ao "deverfazer" do professor não há só um caminho de ida, mas podem haver diversas veredas, atalhos e, principalmente, um vaivém enriquecedor entre ambas as instâncias.

\section{A teoria do reconhecimento na formação do professor}

Mas em que sentido pode ser avaliada a relação entre teoria e prática na formação do professor a partir da ideia de reconhecimento do outro? No texto da dialética do senhor e do escravo, de Hegel, observamos, nesta perspectiva, que há um reconhecimento inicial do predomínio da teorização sobre este vínculo. Positivamente poderíamos pensar na sua repercussão na educação como reconhecimento do significado da teoria, mais especificamente na determinação de seu comando sobre vastos campos do conhecimento, que foi algo importante para ela se instituir com respeito na sociedade. Mas é evidente também aí a repercussão negativa para a educação, quando se preocupou em recuperar e repassar conteúdos formativos, porém alheios ao mundo vivido do aluno, suas representações, identidades e contextos específicos. A partir desta herança enquanto superioridade absoluta do senhor ou domínio da teoria ou do saber conceitual - é que foi criado um modelo de formação defasado nos cursos de licenciatura, excessivamente distanciado do real e que não repercutiu adequadamente no seio de sociedades complexas que vigem sob o princípio da prática.

Já o momento ontológico ou existencial, cujo modelo do logos teorizador se descobre fragilizado, pode ser relacionado também à aventura das descobertas científicas e tecnológicas, as quais impactaram e mudaram o centro do processo de ensino e aprendizagem, ocasionando rupturas, recuos ou avanços que repercutem até hoje. A compreensão sobre a fragilização da teoria pode ser entendida mais especificamente no momento em que ela deixa de fazer sentido e se torna alheia à prática. Porém a saída não pode ser a pura substituição da teoria pela prática, o que poderia resultar na prática vazia de princípios. Forjase assim a imagem do "professor profissional", aquele "informado pela epistemologia da prática, competente para responder às questões de suas tarefas cotidianas" (MORAES, 2009, p. 592).

Por isso, no modelo do reconhecimento ou de abertura ao outro, a compreensão do papel social da escola, por exemplo, não é entendida como uma competência subjetiva a ser desenvolvida ou ativada, conforme apregoa a pedagogia das competências, mas é observada no parâmetro mais amplo da 
relação com outros atores sociais. No caso da sua relação com a universidade, não pode haver subserviência: a escola não pode ser encarada simplesmente como um campo de aplicação prática de conhecimentos ou de desenvolvimento de estratégias profissionais. Menos ainda ser avaliada como um locus mediador da "unidade" entre teoria e prática e sim muito mais como uma instância capaz de produzir conhecimentos legítimos. Reconhecer nela um campo produtor de teoria faz o confronto da formação do professor com o outro da escola tornarse uma necessidade imprescindível. A universidade vai evitar, nesse sentido, encontrar saídas ou subterfúgios para escamotear esta relação, como a criação de bacharelados. E, do lado da escola, haverá uma responsabilização maior pela formação dos estagiários, seus futuros professores, por exemplo.

Há uma presença conflituosa de opostos, sem dúvida, mas que se encontram e se complementam, pois cada um se reconhece na identidade do outro. Afinal, o que está em jogo é uma luta por reconhecimento mútuo ou de (inter)dependência entre teoria e prática. Portanto, reafirmamos que do "deverser", isto é, daquilo que é idealizado enquanto formação na universidade, para o "fazer" do professor não há um caminho sem volta. Mas para isso é necessário que haja confrontos ou lutas de reconhecimento entre ambas as instâncias e igualmente interlocuções, complementos e consensos, pois estes são os postulados básicos do reconhecimento social do outro.

\section{Notas conclusivas}

De acordo com o que falamos até aqui, o equívoco da pedagogia das competências resulta na tecnificação da formação, na medida em que prescreve o desenvolvimento de competências e habilidades, porém em detrimento da formação mais ampla. As competências específicas a serem mobilizadas independem do contexto em que elas ocorrem, suas variáveis e identidades. Há aqui um reconhecimento voltado ao universo do micro, sem dúvida, mas como falta uma perspectiva em relação ao sentido do todo, ou seja, desloca-se da formação a preocupação com os seus aspectos históricos, políticos e sociais, o indivíduo abre mão da dimensão crítica do processo em que está inserido e se transforma num mero executor de ordens sem importância. A perda de referenciais mais amplos de análise pode levar tanto à formação de consciências operativas e padronizadas quanto visionárias e proféticas, igualmente voluntariosas, porém ingênuas, porque sem embasamento no real.

Mas o que é possível reconhecer no ideário pedagógico das competências na formação de professores? Como está ausente nesta pedagogia um confronto com o aspecto teórico (a figura do senhor) em plenitude, talvez pudéssemos, 
por analogia, dizer sobre este assunto o que Hegel afirmou a respeito da liberdade, que ainda permanece sob o domínio da escravidão:

Como nesse caso a pura forma não pode tornar-se essência, assim também essa forma, considerada como expansão para além do singular, não pode ser uma forma universal, conceito absoluto; mas apenas uma habilidade que domina uma certa coisa, mas não domina a potência universal e a essência objetiva em sua totalidade (HEGEL, 2008, p. 151).

Traduzindo para nossa discussão, o alcance da pedagogia das competências, enquanto uso da liberdade, ficou no meio do caminho, se tornando escravo da prática. Como Hegel mesmo diz, se pode reconhecê-la como "apenas uma habilidade que domina uma certa coisa", ou seja, como uma certa técnica. Por isso ela não serve como uma "forma universal", mas é algo sempre limitado ou escravo de um contexto específico. O que lhe falta é "dominar a potência universal", ou seja, fazer a leitura crítica do todo e perceber "a essência objetiva em sua totalidade", isto é, desenvolver uma autocompreensão crítica dos fins para o qual ela serve, que tipo de homem/mulher estaria formando e ainda para que tipo de sociedade ou de mundo opera. No máximo poderá auxiliar na observação do que carece eventualmente ao educando desenvolver, ou seja, como um simples dispositivo ou "habilidade".

Enfim, cremos ter deixado claro que no contexto do paradigma moderno do primado da prática é possível promover uma nova articulação com a teorização sobre a formação do professor, porém sem submissão ao praticismo e menos ainda cultivando uma aversão à dimensão teórica. E que a tentativa de ultrapassar a dicotomia entre teoria e prática, reforçando esta em detrimento daquela, amparada numa Filosofia da Educação de corte construtivista e da pedagogia das competências, fez a legislação sobre a formação de professores recair mais uma vez na instância explicativa do conhecimento. Decididamente, temos aí a "volta por cima" do velho dilema entre teoria e prática, ou seja, temos um reforço à dicotomia que atravessa a preocupação da Filosofia e da Educação durante toda a história ocidental.

A teoria do reconhecimento traz alternativas de caminhos a serem seguidos, pois quando dois extremos são confrontados haverá diversas questões a serem respondidas, com muitas idas e vindas entre teoria e prática e não um caminho linear e sem volta a ser adotado. A qualificação começa com a teoria e a competência pela prática, porém ambos os sistemas não atendem por completo as necessidades pedagógicas por focar excessivamente nos seus extremos. A teoria do reconhecimento do outro vem como um mediador entre 
ambos, através do enfrentamento e da articulação justamente das duas pontas do mesmo processo. Por isso o voo de reconhecimento da coruja de Minerva é panorâmico, contudo não deixa de indicar novos caminhos possíveis de pesquisa. Certamente existem outros "voos" para tornar os grandes objetivos da formação atingíveis em sociedades complexas, mesmo reconhecendo os espaços e tempos cada vez mais limitados de intervenção de que dispomos nesses contextos.

\section{REFERÊNCIAS}

ADORNO, T. W. Notas marginais sobre teoria e práxis. In: ADORNO, Theodor W. Palavras e sinais: modelos críticos. Petrópolis: Vozes, 1995. p. 202-229.

BRASIL, Ministério da Educação. Conselho Nacional de Educação. Parecer CNE/CP 09, 08 de maio de 2001. Diretrizes Curriculares Nacionais para a Formação de Professores da Educação Básica, em nível superior, curso de licenciatura, de graduação plena. Brasília, 2001. Disponível em: <http:// portal.mec.gov.br/cne/arquivos/pdf/009.pdf>. Acesso em: 17/02/2010.

BOMBASSARO, L. C. Entre epistemologia e hermenêutica: a questão da racionalidade e da historicidade do conhecimento e o debate sobre a tese da complementaridade. In: TREVISAN, A. L.; ROSSATTO, N. D. Filosofia e educação: confluências. FACOS-UFSM, 2005. p. 183-196.

COUTINHO, C. P. A qualidade da investigação educativa de natureza qualitativa: questões relativas à fidelidade e validade. Educação Unisinos, v. 12, n. 1, p. 5-15, janeiro/abril 2008. Disponível em: <http://www.unisinos.br/ publicacoes_cientificas/images/stories/pdfs_educacao/vol12n1/ 005a015_art01_coutinho[rev_ok].pdf $>$. Acesso em: 17/02/2010.

DELUIZ, Neise. O modelo das competências profissionais no mundo do trabalho e na educação: implicações para o currículo. Informativo SENAC, v. 27, n. 3, on line, set./dez. 2001. Disponível em: <http://www.senac.br/ informativo/BTS/index.asp>. Acesso em: 12/06/2010.

DOSSIÊ. Parecer da FACED/UFRGS. Parâmetros Curriculares Nacionais. Educação \& Realidade, v. 21, n. 1, p. 229-241, jan/jun 1996, p. 229-241.

DOZOL, M. de S. Da figura do mestre. Campinas, São Paulo: Editora da Universidade de São Paulo, 2003. 
DUARTE, N. As pedagogias do "aprender a aprender" e algumas ilusões da assim chamada sociedade do conhecimento. Revista Brasileira de Educação, n. 18, p. 35-40, set./out/nov/dez. 2001.

FLICKINGER, H.-G. Os graus do reconhecimento social: a crítica de um conceito-chave a partir de G. W. G. Hegel. In: SOBOTTKA, Emil Albert; SAAVEDRA, Giovani Agostini (Orgs.). Reconhecimento e teoria crítica. Civitas, Revista de Ciências Sociais, Porto Alegre, v. 8, n. 1, p. 80-93, jan./abr. 2008.

GRAMSCI, A. Maquiavel, a política e o estado moderno. 7. ed. Rio de Janeiro: Civilização Brasileira, 1989.

HABERMAS, J. Teoría y praxis: estudios de Filosofia Social. Madrid: Tecnos, 1997.

HEGEL, G. W. F. Princípios da Filosofia do Direito. Trad. de Orlando Vitorino. Lisboa: Guimarães Eds. 1986.

. Fenomenologia do espírito. 5. ed. Trad. de Paulo Menezes. Petrópolis: Vozes; Bragança: Ed. Universitária São Francisco, 2008.

KOHAN, W. O. Três lições de filosofia da educação. Educ. Soc., v. 24, n. 82, p. 221-228, abr. 2003.

KUENZER, Acácia. Conhecimento e competências no trabalho e na escola. Disponível em: $<$ http://www.pde.pr.gov.br/arquivos/File/pdf/Textos_Videos/ Acacia_Kuenzer/>. Acesso em: 12/06/2010.

MATOS, O. Imagens sem objeto. In: O iluminismo visionário: Benjamin, leitor de Descartes e Kant. São Paulo: Brasiliense, 1999.

MATTOS, P. C. A sociologia política do reconhecimento: as contribuições de Charles Taylor, Axel Honneth e Nancy Fraser. São Paulo: Annablume, 2006.

MORAES, M. C. M. A teoria tem consequências: indagações sobre o conhecimento no campo da educação. Revista Educação e Sociedade, v. 30, n. 107, p. 585-607, ago. 2009.

MÜHL, E. H. Hermenêutica e educação: desafios da hermenêutica na formação dialógica do docente. In: MÜHL, Eldon Henrique; ESQUINSANI, Valdocir (Orgs.). O diálogo ressignificando o cotidiano escolar. Passo Fundo: UPF Editora, 2004. p. 38-51. 
PEREIRA, S. M. Educação básica e formação docente no contexto das exigências do mundo do trabalho: a formação por competências em análise. Cadernos de Pesquisa, Pelotas: UFPEL, ano 18, n. 33, p. 57-79, maio/agosto 2009.

PERRENOUD, P. Construir as competências desde a escola. Porto Alegre: Artes Médicas, 1999.

. A prática reflexiva no oficio de professor: profissionalização e razão pedagógica. Porto Alegre: Artmed, 2002.

PIMENTA, S. G. Professor reflexivo: construindo uma crítica. In: PIMENTA, S. G.; GHEDIN, E. (Orgs.). Professor reflexivo no Brasil: gênese e crítica de um conceito. 4 ed. São Paulo: Cortez, 2006.

RAMOS, M. N. A pedagogia das competências: autonomia ou adaptação? 3. ed. São Paulo: Cortez, 2006.

RANCIÈRE, J. O mestre ignorante. Belo Horizonte: Autêntica, 2002.

ROCHA, M. Paradoxo da formação: servidão voluntária e liberação. Revista Brasileira de Educação, n. 27, p. 154-171, set./out./nov./dez. 2004.

TESTA, Í. Intersubjetividade, natureza e sentimentos morais: a teoria crítica de A. Honneth e a regra de ouro. In: SOBOTTKA, Emil Albert; SAAVEDRA, Giovani Agostini (Orgs.). Reconhecimento e teoria crítica. Civitas, Revista de Ciências Sociais, Porto Alegre, v. 8, n. 1, p. 94-136, jan./abr. 2008.

TREVISAN, A. L. Terapia de Atlas: pedagogia e formação docente na pósmodernidade. Santa Cruz do Sul: EDUNISC, 2004.

. Um professor no close da intolerância: a pedagogia entre imagem e opinião pública. In: FÁVERO, A.; DALBOSCO, C. A.; MARCON, T. (Orgs.). Sobre filosofia e educação: racionalidade e tolerância: Passo Fundo, RS: Ed. da UPF, 2006. p. 267-281.

ZUIN, A. Sobre a atualidade dos tabus com relação aos professores. Educ. Soc., v. 24, n. 83, p. 417-427, ago. 2003.

Texto recebido em 18 de fevereiro de 2010.

Texto aprovado em 21 de março de 2010. 